\title{
Congenital Hip Dislocation: A Rare Case in Adulthood
}

\author{
Luxação Congénita da Anca: Caso Raro no Adulto
}

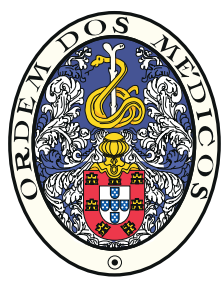

Natália FERREIRA $\triangle^{1}$, Marcelo ABREU ${ }^{2}$, Armando ABREU ${ }^{2}$

Acta Med Port 2018 Jan;31(1):68-68 - https://doi.org/10.20344/amp.9163

Keywords: Adult; Hip Dislocation, Congenital

Palavras-chave: Adulto; Luxação Congénita da Anca

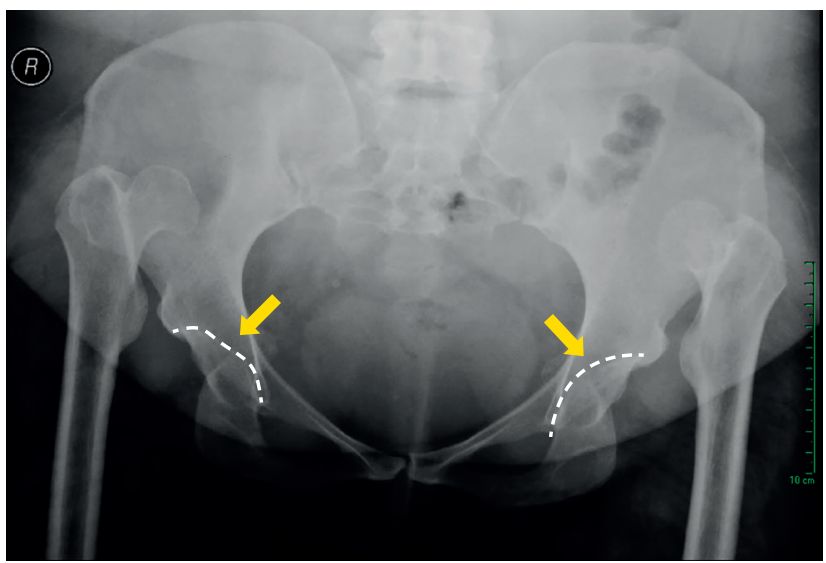

Figure 1 - Radiograph of a young adult with bilateral high hip dislocation. The hypoplastic acetabuli are shown by arrows.

A 29-year-old female presented with a long-standing history of limping and insidious pain on both hips, with no prior history of trauma. Physical examination revealed obvious bilateral hip instability.

Radiograph and additional evaluation with computed tomography (CT) of the hip were performed, depicting a bilateral high hip dislocation with the femoral heads free-floating within the gluteal muscles (Fig.s 1 and 2). Hypoplastic acetabuli and shortening of both femoral necks were observed.

The patient is expecting reconstructive surgery.

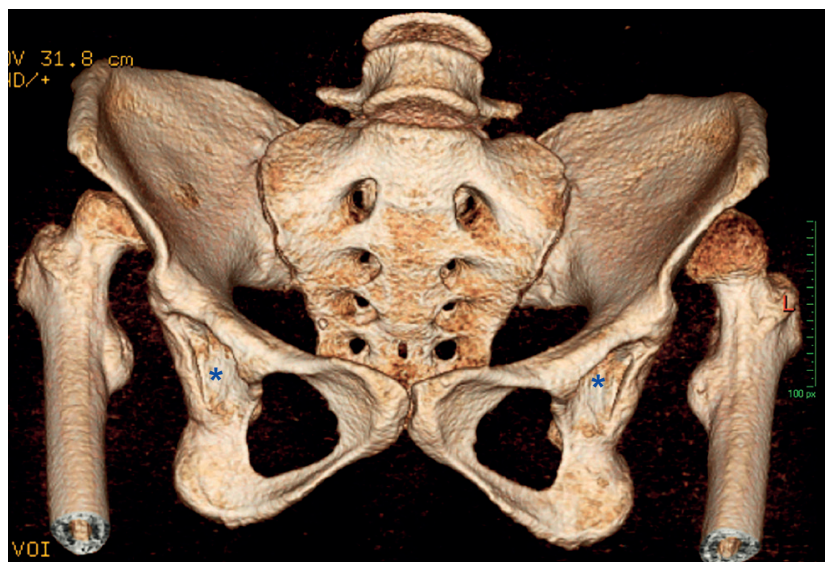

Figure 2 - 3D-CT scan show hypoplastic acetabuli (asterisk) and the femoral heads free-floating within the gluteal muscles.

Three different congenital hip disease types have been described in adults: dysplasia, low dislocation, and high dislocation. ${ }^{1}$ In high dislocation, the femoral head migrates superiorly and posteriorly in relation to the hypoplastic true acetabulum. $^{1}$

Because of routine post-natal ultrasound screening of the hip, congenital high hip luxation has become a rare occurrence in adults. ${ }^{2}$ Undiagnosed patients usually complain of limping and hip pain. Degenerative changes usually develop at around age $30-35 .^{2}$

Reconstructive surgical methods are controversial. ${ }^{3}$

\section{PROTECTION OF HUMANS AND ANIMALS}

The authors declare that the procedures were followed according to the regulations established by the Clinical Research and Ethics Committee and to the Helsinki Declaration of the World Medical Association. DATA CONFIDENTIALITY

The authors declare having followed the protocols in use at their working center regarding patients' data publication. Informed consent was duly obtained from the patient.

CONFLICTS OF INTEREST

All authors report no conflict of interest.

FUNDING SOURCES

This research received no specific grant from any funding agency in the public, commercial, or not-for-profit sectors.

\section{REFERENCES}

1. Hartofilakidis G, Lampropoulou-Adamidou K. Lessons learned from study of congenital hip disease in adults. World J Orthop. 2016;7:785-92.

2. Holinka J, Pfeiffer M, Hofstaetter JG, Lass R, Kotz RI, Giurea A, et al. Total hip replacement in congenital high hip dislocation following iliofemoral monotube distraction. Int Orthop. 2011;35:639-45.

3. Karachalios T, Hartofilakidiss G. Congenital hip disease in adults: terminology, classification, pre-operative planning and management. J Bone Joint Surg Br. 2010;92:914-21.

\footnotetext{
1. Serviço de Imagiologia Geral. Centro Hospitalar Lisboa Norte. Lisboa. Portugal.

2. Centro de Diagnóstico por Imagem. Hospital Mãe de Deus. Porto Alegre. Brasil.

$\triangle$ Autor correspondente: Natália Ferreira. Nataliasanferreira@hotmail.com

Recebido: 03 de maio de 2017 - Aceite: 03 de janeiro de 2018 | Copyright @ Ordem dos Médicos 2018
} 